
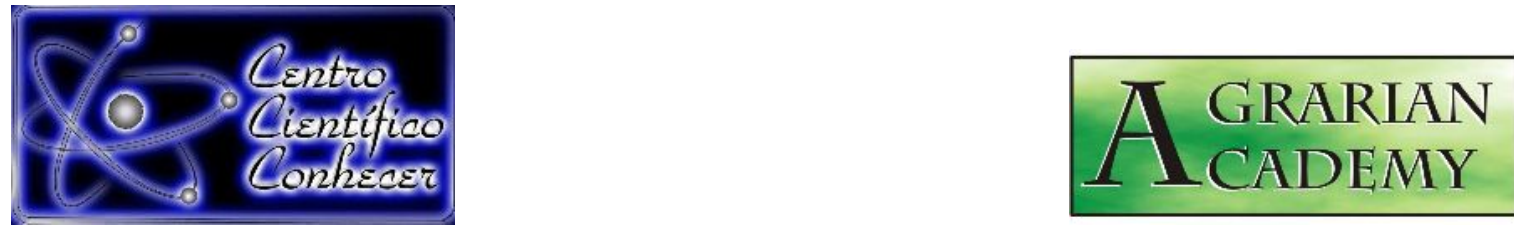

\title{
INDICADORES ECONÔMICOS NA IMPLANTAÇÃO DO CULTIVO DE MOGNO- AFRICANO NO MUNICÍPIO DE CRISTALINA - GO
}

\footnotetext{
Pedro Henrique França Grupioni ${ }^{1}$, Stephany Diolino Cunha ${ }^{1}$, Matheus da Silva Araújo $^{2}$, Andrécia Cósmen da Silva ${ }^{3}$

${ }^{1}$ Discentes do Curso de Engenharia Florestal da Universidade Estadual de

Goiás, Campus Ipameri, Ipameri, GO, Brasil. (phgrupioni@hotmail.com)

${ }^{2}$ Doutorando em Solos e Nutrição de Plantas da Universidade de São Paulo,

Campus Esalq, Piracicaba, SP, Brasil.

${ }^{3}$ Professora mestre da Universidade Estadual de Goiás, Campus Ipameri, Ipameri, $\mathrm{GO}$, Brasil.
}

Recebido em: 14/07/2018 - Aprovado em: 28/07/2018 - Publicado em: 31/07/2018 DOI: 10.18677/Agrarian_Academy_2018a49

\begin{abstract}
RESUMO
Objetivou-se avaliar a viabilidade econômica da implantação do mogno-africano no município de Cristalina-GO através de indicadores econômicos. A área corresponde a 6 hectares no município de Cristalina, Goiás. As mudas de mogno-africano, foram plantadas no espaçamento de $3 \times 2$ metros, em ciclo de uma rotação com idade de corte para 21 anos. Para esse estudo utilizou-se os seguintes indicadores econômicos: Î́ndice Benefício Custo (IBC), Valor Presente Líquido (VPL) e aplicação do Payback econômico do capital investido. Com base nos resultados desses parâmetros, pode-se obter um VPL de $R \$ 1.570 .492,20$ um B/C de 2,73, e um tempo de retorno para o capital investido pelo payback verificado no sétimo ano. Sendo assim, a implantação do mogno-africano apresentou ser economicamente viável, indicando ser uma boa opção de investimento.
\end{abstract}

PALAVRAS-CHAVE: Economia florestal, espécie nobre, plantios florestais, rentabilidade.

\section{ECONOMIC FEASIBILITY OF PLANTING THE AFRICAN-MAHOGANY IN THE MUNICIPALITY OF CRISTALINA-GO}

\begin{abstract}
Objective to evaluate the economic viability of the deployment of the growing African mahogany in the municipality of Crystalline-GO through economic indicators. The area corresponds to 6 hectares in the municipality of crystalline, Goiás. African mahogany seedlings were planted in the spacing of $3 \times 2$ meters, in a rotating cycle with age for 21 years. For this study we used the following economic indicators: index (IBC) Cost Benefit, net present value (NPV) and application of the Economic Payback of capital invested. Based on the results of these parameters, you can obtain an NPV of $\$ 1,570,492.20$ and a $R B / C$ of 2.73 , and a time to return to the AGRARIAN ACADEMY, Centro Científico Conhecer - Goiânia, v.5, n.9; p.499 2018
\end{abstract}


capital invested by the payback checked in seventh grade. Thus, the mahoganyAfrican deployment showed be economically viable, indicating a good investment option.

KEYSWORDS: Economy of Forestry, forest plantations, species noble, profitability.

\section{INTRODUÇÃO}

O setor florestal desempenha função importante na economia brasileira, contribuindo com uma parcela significativa na geração de produtos, tributos, empregos e renda. Sendo assim, os plantios comerciais com espécies nobres vêm ganhando destaque nos últimos tempos. Esse investimento apresenta alto valor econômico no mercado internacional, além de considerar o aspecto ambiental, devido ao crescimento relativamente rápido, promovendo a recuperação de áreas degradadas. Desse modo, devido à carência de informações referentes ao manejo e aos custos de implantação de culturas nobres no Brasil faz-se necessária a realização de estudos que demonstrem a importância e a necessidade de investir nesses plantios (VIRGENS et al., 2015).

Diante disso, a espécie que merece relevância é o mogno-africano. Este pertence à família Meliaceae, é uma árvore de origem africana, possuindo ocorrência natural na África ocidental, em especial na Costa do Marfim, Gana, Togo, Benin, Nigéria, sul de Camarões até a província de Cabinda. É uma espécie heliófila, de caule retilíneo, podendo atingir até 60 metros de altura e diâmetro à altura do peito superior a 2,0 metros (LEMMENS, 2008). A madeira possui alto valor comercial no mercado internacional e grande potencial de uso devido a sua alta densidade e durabilidade, sendo utilizada em diferentes finalidades como movelaria, laminação, instrumentos musicais, construção naval e arquitetura de interiores, (FRANÇA et al., 2016). Além das boas propriedades da madeira, a espécie apresenta diversas propriedades medicinais, como no tratamento da malária (TEPONGNING et al., 2013).

A madeira do mogno-africano vem sendo bastante explorada, pela sua beleza, densidade e valor. Sendo assim, nos dias atuais, os plantios comerciais começaram a ganhar destaque (ARNOLD, 2004), tornando, a espécie do gênero Khaya spp. mais cultivada, principalmente nos Estados do Pará, Minas Gerais, São Paulo, Goiás e Mato Grosso do Sul, devido à importância da madeira, cotação comercial no mercado internacional, e mais ainda, pelo satisfatório desenvolvimento vegetativo quando estabelecido os plantios comerciais (RIBEIRO et al., 2017).

Desse modo, devido à expansão de plantios comerciais utilizando a espécie surge a necessidade de simular estudos de viabilidade econômica que demonstrem de forma clara e rápida se a implantação do projeto será realmente viável. Em qualquer operação que aplique a madeira como matéria-prima é necessário que se faça um planejamento florestal de forma que minimizem os custos, analisando atividades envolvidas no processo de produção para que resulte em menor custo de risco (CARMO et al., 2011).

Diante do exposto, em razão da carência e da importância de estudos econômicos relacionados à viabilidade da implantação do mogno-africano, o presente trabalho teve como objetivo avaliar a viabilidade econômica do mognoafricano no município de Cristalina-GO através de indicadores econômicos. 


\section{Área da implantação}

\section{MATERIAL E MÉTODOS}

O experimento foi projetado na fazenda São José, situada no município de Cristalina. O município está localizado na região leste do estado de Goiás, o clima dominante no município é tropical quente subúmido (Aw), ou seja, com chuvas concentradas no verão conforme a classificação climática de Köppen. São, portanto, duas estações diferentes, uma seca e outra úmida, com temperaturas médias de $23^{\circ} \mathrm{C}$, variando em menos $5^{\circ} \mathrm{C}$ no período frio a $32^{\circ} \mathrm{C}$ no período quente (QUIRINO et al., 2011).

O talhão destinado a implantação do mogno, possui seis hectares e se estabelece próximo a cidade de Cristalina, facilitando o transporte da madeira para comercialização em uma madeireira do município.

\section{Manejo da cultura}

Para a implantação do projeto, foi realizada análise de solo e foi enviada para - laboratório com a finalidade de estabelecer a quantidade necessária de calcário e gesso para correção dos níveis de fertilidade e acidez do solo (Tabela 1).

TABELA 1. Características químicas do Latossolo Vermelho-Amarelo, antes da simulação do projeto.

\begin{tabular}{|c|c|c|c|c|c|c|c|}
\hline M.O & $P$ & K & S & СТC & $\mathrm{AL}^{3+}$ & $\mathrm{H}+\mathrm{AL}$ & V \\
\hline $\mathrm{dag} / \mathrm{Kg}$ & \multicolumn{3}{|c|}{-----mg/dm³------ } & \multicolumn{3}{|c|}{$-{ }^{-----} \mathrm{cmol}_{\mathrm{d}} / \mathrm{dm}^{3}$ - } & $\%$ \\
\hline 4,3 & 23,7 & 106,9 & 4,1 & 8,9 & 0,1 & 3,6 & 59 \\
\hline
\end{tabular}

A espécie de mogno-africano implantado foi o Khaya ivorensis A. Chev., no espaçamento de $3 \times 2$ metros, totalizando 1.667 mudas por hectare, em ciclo de uma rotação com idade de corte para 21 anos. A irrigação foi constante durante os primeiros meses de instalação, ou seja, de outubro a dezembro, foram colocados três litros de água por muda, utilizando um tanque de arrasto.

A técnica de desbaste utilizada do projeto proposta pelo Instituto Brasileiro de Floretas (2018), é o seletivo no quarto, sétimo, décimo quarto e vigésimo primeiro ano, com a finalidade de comercialização para produção de celulose no quarto e sétimo, e para fins de serraria no décimo quarto e vigésimo primeiro ano (AQUINO, 2018). No quarto e sétimo ano serão removidas 500 árvores, no décimo quarto ano 300 árvores e no vigésimo primeiro ano 367 árvores, totalizando 1667 árvores por hectare.

\section{Coleta de dados}

As informações de orçamento foram obtidas pelos autores entre os meses de abril e junho de 2018. O sistema de produção do mogno-africano foi delineado de acordo com as técnicas desenvolvidas por Aquino (2018) e com auxilio de pesquisadores e viveiristas para realizar planilhas no programa Excel com valores atualizados dos gastos e das receitas da cultura com cotações em empresas da região. 


\section{Custos de Implantação}

Para implantação da cultura foram estabelecidos custos de mão de obra, correção de solo, controle de formigas, aplicações para controle de plantas daninhas, formulações de NPK, irrigação e custos com a manutenção da área. Em que, os gastos com essas atividades foram determinados conforme o rendimento médio por homem. O combustível utilizado para realizar em todo o processo de implantação foi estabelecido através da média de consumo de uma fonte de potência pré-determinada, dependendo de cada operação realizada, e o valor do litro do óleo diesel (ESALQ, 2015).

O combate inicial a formiga foi realizado com equipamentos manuais, realizando o primeiro controle antes do plantio e o segundo após dois meses, sendo que, se houver a ocorrência de formigas no decorrer do projeto, o combate irá persistir, com o intuito de controlar um dos principais danos quando se trata de plantios florestais. A aplicação de herbicida foi realizada uma vez antes do plantio e outra após dois meses de estabelecimento da cultura, de forma mecanizada.

\section{Custos de manutenção e venda da madeira}

Os custos adquiridos no projeto com manutenção envolvem os gastos com mão de obra, adubações de cobertura, controle de formigas, controle de plantas daninhas, manutenção de aceiros, manutenção nos primeiros sete anos e manutenção após o desbaste seletivo.

O controle de formigas e daninhas e a manutenção de aceiros foram realizados durante todo o ciclo da cultura e as adubações de cobertura foram realizadas até $04^{\circ}$ ano. Para os cálculos de comercialização foi estimada uma produtividade de $11 \mathrm{~m}^{3} /$ ha comercializada a $R \$ 299,20$, no quarto ano, $56 \mathrm{~m}^{3} / \mathrm{ha}$ comercializada a $R \$ 1.122,00$, no sétimo ano, $90 \mathrm{~m}^{3} / \mathrm{ha}$ comercializada a $R \$$ $1.484,00$, no décimo quarto ano e $292 \mathrm{~m}^{3} / \mathrm{ha}$ comercializada a $R \$ 4.136,00$ no vigésimo primeiro ano (AQUINO, 2018).

\section{Fluxo de Caixa}

O fluxo de caixa é uma importante ferramenta nos estudos realizados em projetos florestais, afinal o mesmo registra as entradas e saídas de dinheiro em um determinado tempo. Desempenhando grande utilidade na avaliação de estudos de viabilidade econômica, pois por meio deste é possível saber se um projeto é rentável e viável (SAMANEZ, 2009). Desse modo, no presente trabalho o fluxo de caixa é representado pelas saídas com os custos de implantação e manutenção da área plantada e pela entrada com a venda da madeira $\left(\mathrm{m}^{3}\right)$ de mogno-africano em um horizonte de 21 anos, no qual, todos os valores foram atualizados mediante fórmulas financeiras de acumulação ou desconto de juros no programa Excel.

\section{Indicadores de Lucratividade}

Os indicadores de lucratividade foram os mesmos considerados por Martin et al., (1998), sendo esses: receita bruta (RB), representada pelo fator multiplicativo da produção pelo preço unitário médio pago aos produtores; receita líquida, resultante da diferença entre a receita bruta e o custo operacional total e o Índice de lucratividade (IL), obtido pela proporção da Receita Bruta (constituída em recursos disponíveis), em relação à Receita Líquida obtida. 


\section{Custos Diretos e Indiretos}

Metodologicamente, o cálculo do custo de produção foi baseado na estrutura do Instituto de Economia Agrícola (MATSUNAGA et al.1976) e usada por outros autores (RAMBO, et al., 2015; NEGRISOLI et al., 2015) que apresenta o custo operacional efetivo (COE), englobando as despesas diretas: mão-de-obra, insumos (mudas, adubos, defensivos e irrigação), além de serviços de terceiros.

As despesas indiretas, como, FUNRURAL, que é o imposto proveniente da comercialização da produção rural, custo de oportunidade da terra que representa o valor que é deixado de ganhar realizando outra atividade no terreno e outros custos $(10 \%)$, foram acrescentados ao COE para totalizar o Custo Operacional Total (COT) do projeto.

\section{Análise econômica}

Os testes de viabilidade contribuíram para o levantamento dos coeficientes técnicos necessários para o cálculo do custo de produção da cultura. Sendo assim, os custos e receitas avaliados, procedeu-se uma análise econômica utilizando os seguintes critérios: Valor Presente Líquido (VPL), Índice Benefício Custo (IBC) e aplicação do Payback.

A relação Benefício/Custo (IBC) está relacionada na comparação entre as receitas e as despesas a uma taxa de juro definida, ou seja, é o lucro obtido para cada unidade de capital investido. Esse indicador pode ser calculado pela relação entre a receita bruta e as despesas do projeto.

$$
\text { Relação } \frac{B}{C}=\sum_{j=0}^{n} \frac{\frac{R_{j}}{1+i^{j}}}{\sum_{j=0}^{n} \frac{C_{j}}{1+i^{i}}}
$$

(Equação 1)

Em que:

$\mathrm{i}=$ Taxa de desconto;

$R \mathrm{j}=$ Receitas oriundas do projeto no ano $\mathrm{j}$;

$\mathrm{C} \mathrm{j}=$ Custos do projeto no ano $\mathrm{j}$;

$\mathrm{n}=$ Vida útil do projeto.

Outra metodologia para mensurar o investimento é o Payback atualizado. Neste cálculo, encontra-se o período que o investimento leva para repor todo o capital aplicado. O payback pode ser determinado pela razão entre o investimento total e o valor do fluxo de caixa (VERGARA et al., 2017).

$$
\text { Payback atualizado }=\frac{\text { Valor do Investimento }}{\text { Valor dos fluxos de caixa }}
$$

(Equação 2)

Já o valor presente líquido (VPL) corresponde ao valor da receita obtida menos os custos totais, quando o valor final for positivo indica que o projeto foi viável, pois o custo total foi menor do que o valor obtido pela receita (VERGARA et al., 2017). 


$$
V P L=\sum_{t=0}^{n} \frac{F C_{t}}{(1+i)^{t}}
$$

(Equação 3)

Em que:

$\Sigma$ : somatório;

FC: fluxo de caixa do período $n$;

i: taxa de desconto;

t: período.

\section{Análise de Sensibilidade}

Procedeu-se uma análise de sensibilidade de forma a projetar possíveis cenários que possam contextualizar uma situação real. A análise de sensibilidade foi projetada para os indicadores: VPL e RB/C. Essa projeção foi disposta em três cenários diferentes: Cenário I: $10 \%$ de aumento nos custos totais; Cenário II: Cenário real, sem alterações na produtividade ou nos custos e Cenário III: 10\% de aumento na produtividade.

\section{RESULTADOS E DISCUSSÃO}

Com base nos dados obtidos, estimou-se a composição dos custos para implantação do mogno-africano em uma área de seis hectares considerando um horizonte de 21 anos com desbastes no quarto, sétimo, décimo quarto e vigésimo primeiro ano (Tabela 2). Observou-se que os insumos totalizaram $R \$ 65.110,00$ dos custos. Sendo que, o investimento que apresentou maior custo foi com a aquisição de mudas. Em que, foram utilizadas 1667 mudas com valor unitário de $R \$ 5,00$, representando $76,80 \%$ do total dos custos com insumos. Os demais custos com insumos representam 23,20 \%, sendo divididos em: irrigação, esterco, calagem e gessagem.

Os custos com fertilizantes foram divididos em: Correção de Cobertura - NPK 20-05-20, correção de Base - NPK 06-30-06, Yoorin Master S, Ekossil, Herbicida Roundup, Formicida no plantio - isca, totalizando custo de R\$24.054,97 representando $0,83 \%$, sendo que as aplicações foram feitas com base nas necessidades da planta e análises de solo.

Outro custo significativo está relacionado aos serviços utilizados para instalação e condução da cultura até a parte final de colheita e transporte. Totalizando ao longo dos 21 anos valor de $R \$ 2.346 .379,00(81,12 \%)$ sendo esses custos divididos em: manutenção nos primeiros sete anos, manutenção após o desbaste, manutenção após primeiro corte, custo de exploração, serragem, transporte e venda da madeira, formicida na manutenção, calagem e gessagem em área total, gradagem em área total, aplicação de herbicidas, aplicação de inseticidas, demarcação de covas e construção e manutenção de aceiros.

Os custos indiretos totalizaram $\mathrm{R} \$ 456.606,02$, representando $15,77 \%$ do custo total, dentre esses custos, tem-se as outras despesas, que representam $10 \%$ do total do custo operacional efetivo. 
TABELA 2 - Estimativa dos custos de implantação do mogno-africano em 6 hectares em um horizonte de 21 anos.

\begin{tabular}{ccc}
\hline Componentes do custo & Valor/ha (R\$) & Participação (\%) \\
\hline Insumos & $65.110,00$ & 2,25 \\
Fertilizantes & $24.054,97$ & 0,83 \\
Serviços & $2.346 .379,00$ & 81,12 \\
\hline Total Custo Operacional Efetivo (COE) & $2.435 .533,97$ & 84,2 \\
\hline Outras despesas (10\%) & $243.543,90$ & 8,42 \\
Custo de Oportunidade da Terra & $86.400,00$ & 2,98 \\
FUNRURAL & $126.662,12$ & 4,37 \\
\hline TOTAL (R\$) & $\mathbf{2 . 8 9 2 . 1 4 9 , 9 9}$ & $\mathbf{1 0 0}$ \\
\hline
\end{tabular}

Dessa forma, é notável a diferença entre os valores gastos com insumos que totalizam $R \$ 65.110,00$ em relação aos valores gastos em serviços, somados em $R \$$ 2.346.379,00 (Tabela 2). Os preços dos serviços são bastante influenciados pela taxa de juro descontada a cada ano, podendo então, apresentar aumento nos custos da implantação da cultura devido a esse fator. Desta forma, é importante que o produtor se atente para o momento certo para contratação de mão-de-obra, da compra dos fertilizantes e o uso conforme a recomendação técnica.

Analisando o fluxo de caixa (Tabela 3 ), verifica-se que no sétimo, décimo quarto e vigésimo primeiro ano o saldo é positivo, mostrando que os valores das receitas já começam a superar os custos, tornando assim a viabilidade econômica do projeto positiva.

TABELA 3. Fluxo de caixa atualizada do mogno-africano em 6 hectares, sobre a taxa de $6,6 \%$ ao ano em um período de 21 anos.

\begin{tabular}{ccccc}
\hline Ano & $\begin{array}{c}\text { Receita } \\
\text { atualizada }\end{array}$ & $\begin{array}{c}\text { Despesa } \\
\text { Atualizada }\end{array}$ & $\begin{array}{c}\text { Fluxo de caixa } \\
\text { atualizado }\end{array}$ & $\begin{array}{c}\text { Fluxo de caixa } \\
\text { acumulado }\end{array}$ \\
\hline 0 & 0 & 87914,99 & $(87914,99)$ & $(87914,99)$ \\
1 & 0 & 11580,67542 & $(11580,67542)$ & $(99495,66542)$ \\
2 & 0 & 10863,673 & $(10863,673)$ & $(110359,3384)$ \\
3 & 0 & 10191,06286 & $(10191,06286)$ & $(120550,4013)$ \\
4 & 15292,43721 & 24907,21327 & $(9614,776057)$ & $(130165,1773)$ \\
5 & 0 & 8968,195579 & $(8968,195579)$ & $(139133,3729)$ \\
6 & 0 & 8412,944444 & $(8412,941444)$ & $(147546,3144)$ \\
7 & 241008,1347 & 51068,2462 & 189939,8885 & 42393,5414 \\
8 & 0 & 7088,589695 & $(7088,589695)$ & 35304,98445 \\
9 & 0 & 6649,708907 & $(6649,708907)$ & 28655,27554 \\
10 & 0 & 6238,000851 & $(6238,000851)$ & 22417,27469 \\
11 & 0 & 5851,783162 & $(5851,783162)$ & 16565,49153 \\
12 & 0 & 5489,477638 & $(5489,477638)$ & 11076,01389 \\
13 & 0 & 5149,603788 & $(5149,603788)$ & 5926,410102 \\
14 & 327417,6819 & 124344,0915 & 203073,5905 & 209000,0006 \\
15 & 0 & 4531,681786 & $(4531,681786)$ & 204468,3188 \\
16 & 0 & 4251,108617 & $(4251,108617)$ & 200217,2102 \\
17 & 0 & 3987,906771 & $(3987,906771)$ & 196229,3034 \\
18 & 0 & 3741,000723 & $(3741,000723)$ & 192488,3027 \\
19 & 0 & 3509,381541 & $(3509,381541)$ & 188978,9211 \\
20 & 0 & 3292,102759 & $(3292,102759)$ & 185686,8184 \\
21 & 1893273,401 & 508468,0161 & 1384805,385 & 1570492,203 \\
\hline Total & $\mathbf{2 4 7 6 9 9 1 , 6 5 5}$ & $\mathbf{9 0 6 4 9 9 , 4 5 1 6}$ & $\mathbf{1 5 7 0 4 9 2 , 2 0 3}$ & $\mathbf{2 2 7 4 7 3 4 , 8 4 3}$ \\
\hline \multicolumn{5}{c}{} \\
\hline
\end{tabular}

AGRARIAN ACADEMY, Centro Científico Conhecer - Goiânia, v.5, n.9; p.505 2018 
O fluxo de caixa demonstra que as despesas produzidas foram maiores nos primeiros sete anos da implantação, esse aumento pode ser justificado pela quantidade de mão de obra, insumos e manutenção empregados nos primeiros anos de plantio. No entanto, a partir do sétimo ano as receitas aumentam significativamente com a venda da madeira, demonstrando viabilidade do projeto. Durante esse tempo, os custos operacionais em seis hectares totalizaram $R \$$ 162.838,75, com um retorno de $\mathrm{R} \$ \mathrm{R} \$ 27.101,14$.

Diante disso, em um trabalho realizado por Castro et al., (2017), em um sistema agroflorestal, demostrou um fluxo de caixa positivo no primeiro ano, devido a presença de cultura temporárias. No entanto, a entrada das espécies madeireiras aumentou a receita desse sistema, demostrando a relevância de tais espécies empregadas na atividade, apontando que a inclusão do componente madeireiro estabelece uma poupança do lucro. Além disso, a introdução de essências florestais de elevado valor econômico nos sistemas agroflorestais contribui no aumento da renda dos produtores, além de impedir a constante migração para novas áreas florestadas, diminuindo o desmatamento (CASTRO, et al., 2017).

De acordo com as análises realizadas das atividades, todos os critérios foram viáveis economicamente (Tabela 4). Ao final do ciclo, tem-se um VPL de $R \$$ 1.570.492,20 e um B/C de 2,73, apresentando-se economicamente viável. Para cada $\mathrm{R} \$ 1,00$ investido a uma taxa de desconto a $6,6 \%$, o retorno financeiro nesse sistema é de $R \$ 1,73$.

TABELA 4. Análise econômica do plantio de mogno-africano em seis hectares.

$\begin{array}{cc}\text { VPL } & 1.570 .492,20 \\ \text { BC } & 2,73 \\ \text { Payback } & 7 \text { anos }\end{array}$

Analisando o mesmo indicador acima, em um trabalho realizado com cacau, mogno-africano e outras essências florestais, Lucena et al., (2016), obtiveram um $\mathrm{B} / \mathrm{C}$ de 11,64 no final de todo o ciclo. Essa diferença pode ser observada pelas despesas que incluíam apenas a manutenção e mão de obra e a presença de outras espécies em consórcio, possibilitando renda alta com taxa baixa de investimento. No entanto, em um monocultivo de mogno-africano, devem-se destacar os gastos realizados com colheita e transporte. No qual, esses representam grande parte dos custos, demonstrando que é um processo oneroso ao longo dos vários ciclos de corte. Sendo que, em trabalhos consorciados, o gasto com colheita apresenta ser relativamente menor devido ao número inferior de árvores por hectare.

O valor do VPL obtido nesse estudo foi superior ao de Silva et al. (2018), analisando um sistema agroflorestal com mogno-africano, apresentando um VPL de $\mathrm{R} \$$ 947.135,11, indicando dessa forma que o cultivo do mogno-africano sem consórcio apresenta rentabilidade em relação aos sistemas agroflorestais.

Analisando essa mesma cultura com os resultados obtidos por Janoselli et al., (2016) em plantios de eucalipto, observa-se que o VPL teve valor negativo de $R \$$ $40.808,70$, a inviabilidade do projeto está relacionada principalmente ao custo de oportunidade da terra e o destocamento da área. No entanto, a atividade de destocamento não foi realizada nesse projeto, tornando assim os valores superiores e positivos ao supracitado.

A análise de sensibilidade realizada (Tabela 5) indicou que o projeto obteve valor presente líquido pessimista de $\mathrm{R} \$ 1.479 .842,26$, e valor otimista, ou seja, um 
cenário positivo com receita de $R \$ 1.818 .191,37$. Essa análise constatou que esses valores demonstram que o projeto, nas condições avaliadas, é economicamente viável, afinal, mesmo se houver aumento nos juros de $10 \%$ o projeto é considerado uma boa opção de investimento.

Em um trabalho realizado com eucalipto, verificou que os valores de produção da madeira, destinada a energia, tornou-se inviável economicamente em um decréscimo de $10 \%$ na produtividade a uma taxa de $6 \%$ ao ano, demonstrando a instabilidade da cultura sobre diferentes cenários a uma taxa menor de juros comparada com o mogno-africano. Constatando dessa forma, a importância da cultura nobre estudada, afinal, o projeto se mostra viável em diferentes situações (COELHO et al., 2016).

TABELA 5. Análise de Sensibilidade do Valor Presente Líquido (VPL) em relação à variação da receita e dos custos do mogno-africano em seis hectares.

\begin{tabular}{ccc}
\hline Cenários & VPL & B/C \\
\hline I & $1.479 .842,26$ & 2,48 \\
II & $1.570 .492,20$ & 2,73 \\
III & $1.818 .191,37$ & 3,00 \\
\hline
\end{tabular}

Cenário I: Cenário pessimista com $10 \%$ de aumento nos custos; Cenário II: Cenário Real; Cenário III: Cenário otimista com aumento de 10\% nas receitas.

Desse modo, percebe-se que o conhecimento dos custos de implantação de qualquer atividade econômica florestal proporciona importante papel no processo de tomada de qualquer decisão. Quando o empreendimento apresenta viabilidade econômica positiva, pode ser considerado um fator favorável para que opte pelo investimento na atividade.

\section{CONCLUSÃO}

A implantação do mogno-africano se mostrou viável com horizonte de planejamento de 21 anos, apresentando valores de VPL, B/C e Payback favoráveis ao produtor.

O plantio da espécie em vários desbastes é uma excelente alternativa para garantir lucro nos anos iniciais de implantação da cultura, ao invés de obter apenas no final do ciclo de corte.

\section{REFERÊNCIAS}

AQUINO, H. Gestão de Florestas de Mognos Africanos. Instituto Brasileiro de Florestas (IBF). 2018. Acessado em: 11 março 2018. Disponível em < http://edu.ibflorestas.org.br/wp-content/uploads/2016/05/higino-aquino-4workshop.pd f>

ARNOLD R. Khaya senegalensis: current use from its natural range and its potential in Sri Lanka and elsewhere in Asia. In: Prospects for high-value hardwood timber plantations in the 'dry' tropics of northern Australia [CD-ROM]. Gympie: Private Forestry North Queensland Association Inc; 2004.

CARMO, F. C. de A.; FIEDLER, N. C.; GUIMARÃES, P. P.; PEREIRA, D. P.; ANDRADE, W. S. de P. Análise de custos da implantação de cultivos de eucalipto 
em áreas acidentadas no sul do Espírito Santo. Cerne, v. 17, n. 4, p. 473-479, 2011. Disponível em: <https://www.scielo.br/pdf/cerne/v17n4/v17n4a05.pdf>. doi: http://dx.doi.org/10.1590/S0104-77602011000400005.

CASTRO, A. A.; KATO, O. R.; MANESCHY, R. Q.; QUEIROZ, J. F. Análise Econômica de Sistemas Agroflorestais em Estabelecimentos Agrícolas Familiares no Sudeste Paraense. Universidade e Meio Ambiente (Revista do Núcleo de Meio Ambiente da UFPA). v. 1, n. 2, p. 74-87, 2017. Disponível em < http://www.reumam.net/index.php/revista/article/view/17>.

COELHO, R. M., LEITE, A. M. P.; LEONEL, M. S.; MATUDA, J. J.; FREITAS, L. C. Avaliação econômica do uso da madeira de eucalipto para diferentes finalidades, na região do alto Jequitinhonha, MG. Floresta, Curitiba, PR, v. 46, n. 2, p. 155-164, 2016. Disponível em < https://revistas.ufpr.br/floresta/article/view/38600/28529>. doi: 10.5380/rf.v46i2.38600

ESALQ - Escola Superior de Agricultura - Luiz de Queiroz. Instruções para coleta e remessa de amostras. $2015 . \quad$ Disponível em:< https://www.solos.esalq.usp.br/coleta.htm> Acessado em: 11 março 2018.

FRANÇA, T.; S.; F.; A. FRANÇA F.; J.; N. ARANGO, R.; A.; Woodward BM, Arantes MDC. Natural resistance of plantation grown African mahogany (Khaya ivorensis and Khaya senegalensis) from Brazil to wood-rot fungi and subterranean termites. International Biodeterioration e Biodegradation. 2016 107:88-91. Disponível em < https://www.fs.usda.gov/treesearch/pubs/53612> doi: http://dx.doi.org/10.1016/j.ibiod.2015.11.009.

IBÁ - Indústria Brasileira de Árvores. 2017. Relatório Ibá 2017. Disponível em: $<$ http://iba.org/images/shared/Biblioteca/IBA_Rela torioAnual2016_.pdf>. Acesso em: 25 março. 2018.

JANOSSELI, H. R. D.; HARBS, R.; MENDES, F. L. Viabilidade econômica da produção de eucalipto no interior de São Paulo. Revista iPecege. v. 2, n. 2, 24-45, 2016. Disponível em < https://revista.jpecege.com/Revista/article/view/65/0 > doi: 10.22167/r.ipecege.2016.2.24.

LEMMENS, R. H. M. J. 2008. Khaya ivorensis A. Chev. [Internet] registro de Protabase. Louppe, D., Oteng-Amoako, A.A.; Brink, M. (Eds). PROTA (Recursos Vegetais da África Tropical / Recursos de l'Afrique vegetal estropicale), Wageningen, Holanda. Disponível em <http://database.prota.org/search.htm>. Acesso em: 12 abr. 2018.

LUCENA, H. D.; PARAENSE, V. C.; M, C. H. A. Viabilidade Econômica de um sistema agroflorestal com cacau e essências florestais de alto valor comercial em Altamira -PA. Revista de Administração e Negócios da Amazônia, v.8, n.1, 2016. Disponível em http://www.periodicos.unir.br/index.php/rara/article/view/1566> doi: 10.18361/2176-8366/rara.v8n1p73-84. 
MATSUNAGA, M.; BEMELMANS, P. F.; TOLEDO, P. E. N. de; DULLEY, R. D.; OKAWA, H.; PEDROSO, I. A. Metodologia de custo de produção utilizada pelo IEA. Agricultura em São Paulo, São Paulo, v. 23, t. 1, p. 123-139, 1976. Disponível em < http://www.iea.sp.gov.br/out/verTexto.php?codTexto=11566>.

MARTIN, N. B. SERRA, R. OLIVEIRA, ÂNGELO, J. R.; OKAWA, H. Sistema integrado de custos agropecuários - CUSTAGRI. Informações Econômicas, São Paulo, v. 28, n. 1, p. 7-28, 1998. Disponível em < http://www.iea.sp.gov.br/ftpiea/ie/1998/tec1-0198.pdf>.

NEGRISOLI, R. M.; CECHINATTO, F. H.; BISSOLI, M. J.; ROSESTOLATO, L. L. R.; SABBAG, O. J. Viabilidade Econômica no Cultivo de minitomate sweet grape no Município de Casa Branca/sp. Enciclopédia Biosfera, Centro Científico Conhecer Goiânia, v.11 n.21; p. 193, 2015. Disponível em < http://www.conhecer.org.br/enciclop/2015b/agrarias/viabilidade\%20economica\%20n ०\%20cultivo\%20de\%20minitomate.pdf>.

QUIRINO, D. T.; SALES, I. F. de; SILVA, O. F. Aplicação do sensoriamento remoto para análise temporal em agriculturas irrigadas por pivô central no município de Cristalina-GO. Simpósio Brasileiro de Sensoriamento Remoto - SBSR, XV, 2011, Curitiba, PR, Brasil. Anais..., INPE, Curitiba, 30 de abril a 5 de maio de 2011, p. 154.

RAMBO, J. R.; TARSITANO, M. A. A.; KRAUSE, W.; LAFORGA, G.; SILVA, C. Análise Financeira e Custo de Produção de Banana-maçã: um estudo de caso em Tangará da Serra, Estado do Mato Grosso. Informações Econômicas, SP, v. 45, n. 5, set./out. 2015 . Disponível em http://www.iea.sp.gov.br/ftpiea/publicacoes/ie/2015/tec4-1015.pdf>

RIBEIRO, A.; FERRAZ FILHO, C. A.; SCOLFORO, J. R. S. O Cultivo do Mogno Africano (Khaya spp.) e o Crescimento da Atividade no Brasil. Floresta e Ambiente, Seropédica, v.24, n.1, p.1-11, 2017. Disponível em < http://www.scielo.br/pdf/floram/v24/2179-8087-floram-24-e00076814.pdf> doi: http://dx.doi.org/10.1590/2179-8087.076814.

SILVA, A. S. O.; OLIMPIO, S. C. M.; SARGES, S. G.; ALMEIDA, W. L. L.; PARAENSE, V. C. Viabilidade Econômica de um Sistema Agroflorestal no município de Breu Branco - PA. Inter Espaço. Grajaú - MA, v. 4, n 13, p 169-183, 2018 Disponível em < http://www.periodicoseletronicos.ufma.br/index.php/Interespaco/artic le/view/8363/5368> doi: http://dx.doi.org/10.18764/2446-6549.v4n13p169-183.

SAMANEZ, C. P. Engenharia econômica. São Paulo: Pearson Prentice Hall, 2009. $210 \mathrm{p}$.

TEPONGNING, R.; S.; YERBANGA, S.; R.; DORI. G.; U.; LUCANTONI. L.; LUPIDI, G.; HABLUETZEL, A. In vivo efficacy and toxicity studies on Erythrina senegalensis and Khaya ivorensis used as herbal remedies for malaria prevention in Cameroon. European Journal of Medicinal Plants 2013; 3(3): 454-464. Disponível em < http://www.sdiarticle1.org/prh/EJMP_13/2013/1378106782-1-Original\%20Manuscript. pdf > doi: http:// dx.doi.org/10.9734/ËJMP/2013/3928. 
VERGARA, W. L H.; OLIVEIRA, J. P. C.; BARBOSA, F. A.; YAMANARI, J. S. Análise de viabilidade econômico-financeira para aquisição de uma unidade de armazenagem de soja e milho. GEPROS. Gestão da Produção, Operações e Sistemas, n.1, p. 41-61, 2017. Disponível em: <https://revista.feb.unesp.br> doi: 10.15675/gepros.v12i1.1598.

VIRGENS, A. P.; FREITAS, L. C.; LUZ, D. S.; MOREIRA, A. C. D. Análise Econômica e de Sensibilidade em Projetos de Reflorestamentos no Estado da Bahia. Enciclopédia Biosfera, Centro Científico Conhecer - Goiânia, v.11 n. 21. p.120, 2015. Disponível em < http://www.conhecer.org.br/enciclop/2015b/agrarias/an alise\%20economica\%20e\%20de\%20sensibilidade.pdf>. 